\title{
POLÍTICAS PÚBLICAS HABITACIONAIS E A PRODUÇÃO DO ESPAÇO URBANO DE RIO GRANDE/RS
}

\author{
Ana Cristina Duarte de Aguiar* \\ *Geógrafa pela Universidade Federal do Rio Grande (FURG). Doutora em Geografia (Área de Concentração Análise Territorial) pela Univer- \\ sidade Federal do Rio Grande do Sul (UFRGS).
}

Recebido em 06/2016. Aceito para publicação em 07/2016.

Versão online publicada em 06/2018 (http://seer.ufrgs.br/paraonde)

\begin{abstract}
Resumo: 0 trabalho a seguir tem por objetivo fazer uma abordagem sobre o processo de produção do espaço urbano da cidade do Rio Grande, levando em consideração as políticas públicas habitacionais que foram sendo criadas para as camadas da população de menor poder aquisitivo. A cidade, dentro de uma lógica capitalista, é produzida de acordo com as necessidades relacionadas às atividades econômicas que as caracterizam. Poucas ações são pensadas no sentido de melhorar a qualidade de vida de sua população. Considerando a cidade como um espaço coletivo, um lugar de encontro entre os indivíduos e de vivência cotidiana, onde se consolida um modo de vida, além das relações sociais voltadas ao seu modo de produção. Desenvolvemos este trabalho, através de uma pesquisa que levou em consideração os ciclos econômicos pelos quais a cidade do Rio Grande passou, buscamos identificar também as políticas públicas habitacionais desenvolvidas para as classes populares na cidade. Para fins de análise, identificamos dois períodos relacionados às políticas urbanas voltadas a habitação popular: o primeiro que estende-se dos anos 1930 à 1986; o segundo, caracterizado pela autora, como uma nova política urbana, que teve início com o processo de redemocratização da sociedade e atuação dos movimentos sociais, quando são criados uma série de instrumentos de planejamento e gestão do solo urbano. Procuramos fazer uma breve análise das mudanças qualitativas na cidade a partir deste novo momento. A partir do início deste século, a cidade do Rio Grande passa a vivenciar um novo ciclo econômico através da implantação do Polo Naval, momento em que a cidade passa a receber uma grande demanda de trabalhadores, ressurgindo os problemas urbanos que foram sendo criados ao longo de toda a sua história, desta forma buscamos analisar como o poder público atuou frente à este novo marco regulatório, no sentido de produzir uma cidade além de uma lógica capitalista, onde se leve em consideração a cidade como um espaço de produção de vidas.
\end{abstract}

Palavras-chave: Habitação, Políticas Públicas, Cidade.

\section{HOUSING POLICIES AND THE PRODUCTION OF URBAN SPACE IN THE CITY OF RIO GRANDE}

\begin{abstract}
The following work aims to approach the process of production of urban space in the city of Rio Grande, taking into account the housing policies which have been implemented for the population of lower income. The city, within the logic of capitalism, is produced according to the needs of the economic activities which typify them; few initiatives take place in order to improve the quality of life of its population. Considering the city as a collective space, a place where individuals meet up and live, where a way of life is consolidated, as well as social relationships towards the city's production mode. We developed this study through a research which considered the economic cycles to which the city of Rio Grande was submitted, we sought to identify the housing policies geared to the population of lower income in the city. For such analysis, we found two periods related to urban policies on popular housing, the first one started in the 1930s up to 1986. The second period, described by the author, as a new urban policy, began with the process of redemocratization of society and engagement in social movements, where planning and management of urban soil took place, we carried out a brief analysis of the qualitative changes in the city as of this new moment. The city of Rio Grande has gone, since the beginning of this century, through a new economic cycle due to the launch of the naval shipbuilding hub, when the city receives a sharp demand for workers, arising, then, the urban problems which were created through its history, thus we intend to analyze the political power and its role in this new regulatory framework, as a means of producing a city beyond the logic of capitalism, where the city is regarded as a space of producing lives.
\end{abstract}

Key-words: Housing, Public Policies, City. 


\begin{abstract}
Resumen: El trabajo siguiente tiene por objetivo hacer un abordaje con respecto al proceso de producción del espacio urbano de la ciudad de Rio Grande, llevando en consideración las políticas públicas habitacionales que fueran siendo creadas para las camadas de la población de menor poder adquisitivo. La ciudad, dentro de una lógica capitalista, es producida de acuerdo con las necesidades relacionadas a las actividades económicas que las caracterizan. Pocas acciones son pensadas con el fin de mejorar la calidad de vida de su población. Considerando la ciudad como siendo un espacio colectivo, un sitio de encuentro entre los individuos y de vivencia cotidiana, donde se consolida un modo de vida, además de las relaciones sociales vuelto a su modo de producción. Desarrollamos este trabajo a través de una investigación que ha llevado en cuenta los ciclos económicos por los cuales la ciudad de Rio Grande ha pasado, hemos buscado identificar también las políticas públicas habitacionales desarrolladas para las clases populares en la ciudad. Para fines de análisis, hemos identificado dos períodos relacionados a las políticas urbanas destinadas a la habitación popular, el primer de los años 1930 hasta 1986. El segundo, caracterizado por la autora, como una nueva política urbana, que tuvo inicio con el proceso de redemocratización de la sociedad y actuación de los movimientos sociales, cuando son creados una serie de instrumentos de planeamiento y gestión del solo urbano. Procuramos hacer una breve análisis de las mudanzas cualitativas en la ciudad a partir de este nuevo momento. Dentro de nuestros objetivos está desarrollar un trabajo que muestre cuales los cambios efectivos de la calidad de vida en la ciudad. La ciudad de Rio Grande ha pasado a partir del inicio de este siglo a vivenciar un nuevo ciclo económico a través de la implantación del Polo Naval, momento en que la ciudad empieza a recibir una gran demanda de trabajadores, resurgiendo los problemas urbanos que fueran siendo creados a lo largo de toda su historia. Por lo tanto, buscamos hacer un análisis de cómo el poder público actuó frente a este nuevo marco reglamentario, en el sentido de producir una ciudad más allá de una lógica capitalista, donde se lleve en consideración la ciudad como un espacio de producción de vidas.
\end{abstract}

Palabras-clave: Habitación, Política públicas, Ciudad.

\section{Introdução}

A cidade do Rio Grande, a mais antiga do estado do Rio Grande do Sul, é um importante polo portuário e industrial. 0 município possui mais de 200 mil habitantes e nele situa-se o único porto marítimo do estado. Polo industrial, onde se destacam a petroquímica (Refinaria Riograndense), indústrias de fertilizantes, de pescado e o recente Polo Naval, o município está entre os cem maiores produtos internos brutos municipais brasileiros, além de ser a quinta economia do estado. Esta posição no cenário econômico estadual foi atingida recentemente, com a implantação do Polo Naval em 2004, o qual iniciou sua trajetória com a construção da plataforma de petróleo P-53. Anterior a este processo, ao longo do século $\mathrm{XX}$, a cidade já havia passado por outros ciclos de riqueza através de grandes obras no seu porto e da implantação de grandes projetos industriais. Todos estes ciclos atraíram migrações de trabalhadores e impactaram fortemente no espaço urbano e, especialmente, na questão habitacional.

Neste sentido, o artigo tem por objetivo fazer uma abordagem sobre o processo de produção do espaço urbano da cidade do Rio Grande, levando em consideração as políticas públicas habitacionais que foram sendo criadas para as camadas da população de menor poder aquisitivo. A cidade, dentro de uma lógica capitalista, é produzida de acordo com as necessidades relacionadas às atividades econômicas que as caracterizam. Poucas ações são pensadas no sentido de melhorar a qualidade de vida de sua população. Desenvolvemos este trabalho, através de uma pesquisa que levou em consideração os ciclos econômicos pelos quais a cidade do Rio Grande passou, nos quais buscamos identificar as políticas públicas habitacionais desenvolvidas para as classes populares na cidade.

Para fins de análise, identificamos dois períodos relacionados às políticas urbanas voltadas a habitação popular, o primeiro que tem início nos anos 1930, estendendo-se até 1986. E o segundo, após 1986, caracterizado pela autora, como "uma nova política urbana", que teve início com o processo de redemocratização da sociedade e com a atuação dos movimentos sociais, quando, em nível nacional, com a nova Constituição (1988) e o posterior Estatuto da Cidade (2001) são criados uma série de instrumentos de planejamento e gestão do solo urbano. Procuramos fazer uma breve análise das mudanças qualitativas na cidade a partir deste novo momento. A cidade do Rio Grande passa, a partir do início do presente século, a vivenciar um novo ciclo econômico através da implantação do Polo Naval, momento em que a cidade passa a receber umagrande demanda de trabalhadores, ressurgindo os problemas urbanos que foram sendo criados ao longo de toda a sua história. Desta forma, a pesquisa aqui apresentada buscou analisar como o poder público atuou (ou não) frente à esta nova realidade social, econômica e institucional, no sentido de produzir uma cidade além de uma lógica capitalista do mercado, onde se leve em consideração a cidade como um espaço de produção de vidas

\section{A produção do espaço urbano na cidade do Rio Grande}

A cidade, embora exista anteriormente ao processo de industrialização, este trouxe importantes mudan- 
ças para o seu processo de produção, principalmente no que se refere à produção de áreas habitacionais.

Quando abordamos o caso da cidade do Rio Grande, este não difere de tantos outros modelos de produção das cidades brasileiras, onde pouca atenção foi dada em relação às políticas habitacionais voltadas as classes menos favorecidas da população.

Podemos afirmar que, o primeiro ciclo industrial de Rio Grande teve início no ano de 1874, marcado pela implantação do primeiro parque fabril. Este primeiro período estende-se até o ano de 1930, momento que marcou o início de importantes transformações no espaço urbano desta cidade.

Esse período, caracterizado por uma fase de intensa industrialização na cidade e no Estado do Rio Grande do Sul, refletiu no número de habitações, uma vez que trouxe consigo um grande contingente de mão de obra. Projetos desenvolvidos na cidade acabaram por transformar o pequeno Porto do Rio Grande em um dos maiores portos brasileiros.

Como exemplo nessa primeira fase de industrialização, podemos destacar a fundação da Companhia União Fabril Rheingantz, voltada a produção de tecidos de lã. A atividade deixou marcas na produção do espaço da cidade dentro dos moldes das relações capitalistas, pois aqueles trabalhadores de menor poder aquisitivo acabavam residindo em vila operárias próximas à fábrica. Àqueles que ocupavam cargos de maior importância, como os mestre e engenheiros, acabavam por ocupar outro tipo de habitação, construída em outro padrão arquitetônico, de acordo com seus países de origem.

Percebemos que a localização das moradias era próxima à área industrial, hoje o prédio dessa antiga indústria encontra-se bastante degradado e a avenida onde está localizado, conta com uma variedade de atividades urbanas, comerciais, de lazer e de serviços, tornando-se uma área central bastante valorizada da cidade.

A forma de produção do espaço da época caracterizava-se pelo controle da mão de obra que era utilizada nas indústrias, o oferecimento de moradias era uma forma de garantir a disciplina do trabalhador, uma vez que ele dependia daquela estrutura oferecida pelo empregador.

Com isso podemos perceber que o processo de produção do espaço da cidade está diretamente relacionado ao modo de vida em que os trabalhadores estão inseridos.

A construção dessas moradias decorria da intenção de facilitar o controle sobre o funcionário, assim como diminuir o gasto com transporte, que na época era precário e lento, já que os principais meios de locomoção eram os bondes ou veículos de tração animal. De certa forma, tais práticas escamoteavam por meio de medidas assistencialistas a coerção econômica imposta aos trabalha- dores, isto é, o controle sobre os operários extrapolava os muros da fábrica (PESAVENTO apud MARTINS; PIMENTA, 2004, p. 88)

No tocante a expansão urbana, essa é resultado da instalação de importantes complexos industriais que acabaram trazendo mudanças na estrutura da cidade, com a construção de diversos tipos de moradias em torno das fábricas. Percebe-se nesse período uma forte atuação das empresas no sentido de provimento de habitações, foram construídas moradias no entorno das fábricas com o objetivo de atender aos operários situados nas escalas hierárquicas inferiores e com menor poder aquisitivo.

Embora com as ações da empresas, uma grande parte do operariado, não teve o mesmo acesso e, acabou por ocupar de forma precária a zona urbana de Rio Grande.

Assim, percebemos que desde sua origem a cidade acabou produzindo, devido ao grande contingente de trabalhadores, uma forma de ocupação muito precária, refletindo no aumento de áreas aterradas e ocupadas irregularmente, principalmente após o término desse período considerado áureo, que terá como consequência o fechamento das indústrias e o aumento do desemprego, deixando muitas parcelas da população à margem do acesso à vida urbana com o mínimo de infraestrutura adequada. Muitos que haviam vindo para a região devido às condições de trabalho que eram oferecidas acabaram não voltando para suas cidades de origem, o que acabou por contribuir com o contingente de pessoas que foram absorvidas nas camadas mais pobres da população rio-grandina.

Percebemos que até este momento, os agentes públicos não desenvolveram nenhuma ação eficaz no sentido de solucionar o problema da moradia para os trabalhadores.

Em uma sociedade em que a terra urbana é vista como uma mercadoria, muitas pessoas ficam à margem da condição de comprá-la e não lhes resta outra alternativa a não ser a ocupação de áreas, processo comum em qualquer cidade brasileira, agravado pela falta de políticas públicas destinadas à moradia das classes menos favorecidas.

A habitação é um desses bens cujo acesso é seletivo: parcela enorme da população não tem acesso, quer dizer não possui renda para pagar o aluguel de uma habitação decente e, muito menos, comprar um imóvel. Este é um dos mais significativos sintomas de exclusão que, no entanto, não decorre isoladamente: correlatos a ela estão a subnutrição, as doenças, o baixo nível de escolaridade, o desemprego ou o subemprego e mesmo o emprego mal remunerado (CORREA, 2002, p. 29).

Diante desse contexto a habitação, que era em muitos casos provida pelas empresas com o objetivo 
de garantir a força de trabalho, acabou se tornando um privilégio daquelas camadas que podiam pagar por ela, e as formas encontradas acabam sendo o aluguel em locais mais afastados e com pouca infraestrutura ou a ocupação de áreas. 0 processo de periferização, caracterizado pela expulsão das classes mais pobres do centro e das áreas mais valorizadas é uma realidade na sociedade urbano industrial que emerge. Segundo Kowarick (2009, p. 28):

Deve-se dizer que com a chegada de melhorias urbanas em áreas antes desprovidas, eleva-se seu preço econômico à medida que decai seu ônus social. No momento em que ocorre esse processo de valorização, essas áreas, antes acessíveis a faixa de remuneração mais baixa, tendem a expulsara maioria dos locatários, os proprietários que não puderem pagar o aumento de taxas e impostos, transformando-se em zonas para camadas melhor remuneradas. Ademais, elas se fecham para o contingente de novos moradores pauperizados de benfeitorias, uma habitação para alugar ou comprar um terreno para construir a sua "casa própria": reproduz-se, assim, um padrão de periferização que aumenta enormemente os assim denominados custos de urbanização, pois sempre são geradas novas áreas longínquas e rarefeitas de população que deverão ser - algum dia - providas com um mínimo de serviços públicos. Reproduz-se também uma forma de expansão urbana extremamente dilapidadora para aqueles que não têm recursos econômicos e políticos para pagar o preço de um progresso altamente espoliativo.

A classe de trabalhadores que surgiu nesse período em Rio Grande, assim como em outras regiões, não teve as mesmas oportunidades de moradia. A forma como aconteceu o processo de produção do espaço urbano não possibilitou as mesmas condições para as pessoas, gerando uma camada de excluídos do acesso à moradia e às condições dignas de habitar a cidade. As áreas consideradas melhores e mais bem dotadas de infraestrutura em Rio Grande estavam localizadas no até então centro da cidade, sendo exclusividade de quem tinha condições de pagar por elas.

Podemos afirmar que até 1950 o crescimento da cidade se deu de forma contínua e a partir desse ano muitas indústrias na cidade começaram a fechar e adiminuir a sua produção, devido à retração do mercado internacional e à forte concorrência com produtos de outras regiões, o que trouxe grande desemprego para a cidade e agravou o processo de exclusão e ocupação irregular do solo urbano. A partir de 1950, a cidade passou por um período de desaceleração econômica, caracterizado pelo fechamento de várias empresas, diminuindo a oferta de trabalho e aumentando o desemprego.
Assim, a cidade passa por um período de estagnação econômica que se estende até o início das atividades que marcaram os investimentos voltados à criação do Polo Naval, no ano de 2004, através da construção da plataforma P-53, para a Petrobrás.

Além do problema da falta de moradia, o período caracterizado pela implantação do Polo Naval, fez ressurgir problemas como a ocupação irregular de áreas, gerando uma fase de novos conflitos pelo uso do solo urbano, uma vez que, como já descrito, muitas áreas próximas as atividades portuárias e industriais foram sendo ocupadas e incorporadas ao tecido urbano em ciclos anteriores, já que poucas ações foram desenvolvidas no sentido de atender esta demanda habitacional. Neste momento, a cidade passa a receber uma grande

demanda de trabalhadores, o que aumenta ainda mais a demanda por habitação. Podemos citar o exemplo da Quip, empresa criada pela sociedade de outras três, UTC Engenharia, IESA Óleo e Gás e Construtora Queiróz Galvão, responsáveisinicialmente pela construção da P-53, que trabalhava apenas com 30\% de sua mão de obra oriunda de Rio Grande, todo o restante vinha de outras regiões do país.

Os investimentos no setor naval em Rio Grande fizeram ressurgir o crescimento econômico e aampliação da infraestrutura de seu Porto. A P-53, considerada a obra pioneira da fabricação e montagem de plataformas na cidade do Rio Grande, é a maior plataforma da Petrobrás a operar em águas brasileiras e é responsável por mais de $10 \%$ do petróleo nacional.

Com os investimentos diretos na indústria naval em Rio Grande, outros setores da economia também passam por um processo de aquecimento, principalmente o imobiliário e hoteleiro. Em relação à produção de habitação, incentivada pelos recursos que estavam sendo investidos pelo governo federal através do Ministério das Cidades em programas habitacionais, temos como resultado um aumento no número dos imóveis na cidade. Como apontamos, a cidade carece não só de produção como também de qualificação de moradias. Empresas estão realizando e planejando projetos para atender essas demandas, o que impulsiona a construção civil no município.

Os reflexos no mercado imobiliário são marcantes, pois Rio Grande caracteriza-se por uma forte concentração nesse setor, e com o Polo Naval os preços dos terrenos subiram muito, chamando atenção de especuladores que passaram a comprar imóveis na cidade. As próprias empresas manifestaram interesses em investir no setor imobiliário, a empresa Engevix, também responsável pelas atividades do Polo, expressou a intenção de construir um complexo habitacional com seis mil residências , um centro comercial, um hospital e um hotel localizado entre a praia do Cassino e o Polo Naval, o que acabou não acontecendo.

Mesmo com tantos investimentos que caracterizaram esta fase, as ações voltadas para a produção habitacional não foram significativas, deixando mais uma 
vez uma grande demanda de trabalhadores sem acesso a moradia.

Atualmente, o Polo Naval de Rio Grande não opera mais com o número de trabalhadores e empresas prometidos, fatores relacionados à crise econômica e política pela qual o país passa atualmente, e também a própria mobilidade das ações nos territórios em tempos de globalização econômica. Mais uma vez então a cidade passa a refletir os momentos tanto de crescimento e declínio econômico.

Como percebemos, a realidade da cidade do Rio Grande, não difere das cidades brasileiras, caracterizada pela escassez ou até ausência de políticas públicas relacionadas à habitação popular.

A seguir faremos uma breve análise de como o poder público vem atuando em políticas voltadas a habitação ao longo dos ciclos econômicos vivenciados pela cidade do Rio Grande.

\section{A cidade e as políticas públicas voltadas à habita- ção popular}

Podemos afirmar que não só na cidade do Rio Grande, mas na maior parte das cidades brasileiras, foram as atividades econômicas que impulsionaram a produção do seu espaço. Poucas foram as ações do poder público ou iniciativa privada no sentido de prover uma infraestrutura necessária para uma melhor qualidade de vida do cidadão urbano.

As primeiras ações governamentais voltadas para habitação popular surgiram a partir dos anos 1930, em um contexto de aumento das massas de trabalhadores e moradores das cidades, assim como de legitimação da figura do Estado.

Na década de 1960, foi criado o Banco Nacional de Habitação (BNH) e foi instituído o Sistema Financeiro de Habitação (SFH). Em Rio Grande, as ações desses agentes foram materializadas pela criação dos primeiros loteamentos destinados à população de baixa renda, caracterizando-se também na primeira ação governamental na cidade, que teve como objetivo o investimento de recursos na área de habitação. Até o fechamento do BNH, no ano de 1986, foram construídas em Rio Grande cerca de 3.993 habitações destinadas a população de baixa renda.

Em relação à atuação do Estado, através do BNH em Rio Grande, completa Soares e Amaral (1997, p. 55):

Em Rio Grande, a primeira cooperativa a HABICOOP (Coop. Habitacional dos Operários de Rio Grande), constitui-se em 1968, tendo construído um grande número de apartamentos e conjuntos de casas até 1973. A partir deste ano começa a atuar a ESTICOOP (Coop. Habitacional dos Trabalhadores Portuários de Rio Grande), vinculada ao Sindicato dos Estivadores, que vai construir os maiores conjuntos habitacionais da cidade na década de 80. [...] No total, as cooperativas habitacionais construíram cerca de dois terços das unidades habitacionais dos condomínios verticais de Rio Grande, demonstrando o grau deimportância que o financiamento público apresenta na construção da habitação de uma ampla parcela de trabalhadores.

Em meio às ações dessa política habitacional foi construído em Rio Grande um dos maiores conjuntos residenciais de apartamentos, com um total de 800 unidades habitacionais, o Condomínio Waldemar Duarte, no Trevo da cidade, às margens da rodovia RS-734.

Após a extinção do BHN (1986) foi significativa a paralisação dos empreendimentos de construção de moradias, com o aumento do tempo de construção (entre a aprovação do projeto e a entrega de casas) e a diminuição da dimensão dos condomínios construídos, o que demonstra que empresas procuram redimensionar a sua atuação quando ficam sem proteção estatal (SOARES; AMARAL, 1997, p. 57).

Na década de 1980 surgiram novos loteamentos populares em áreas próximas às Rodovias Rio Grande/ Pelotas e Rio Grande/Cassino, e no balneário Cassino.

A partir dos anos 1980 foi constatada uma nova oferta de lotes urbanizados com moradias do tipo popular, tais como PROFILURB, PRÓ-MORAR E COHAB. Essa iniciativa tinha como objetivo minimizar o problema do déficit habitacional na cidade, principalmente para a população de baixa renda.

A economia da cidade passava por um processo de desaceleração no final dos anos 1980, período que se estendeu até o início deste século, quando começaram os investimentos relacionados ao Polo Naval, caracterizando um novo ciclo de desenvolvimento que acabou fazendo ressurgir o problema da falta de moradia, principalmente para as camadas populares.

No que se refere as políticas públicas voltadas a habitação, identificamos o período entre os anos 1930 até o de 1986, marcado pela extinção do BNH, como um primeiro momento de planejamento e execução no sentido de provimento de habitações populares.

A produção do espaço da cidade, até os anos 1930, ocorreu sem nenhuma política governamental para produção de habitação popular. As pessoas viviam nas proximidades das fábricas em bairros, na maioria das vezes produzidos pelos proprietários e responsáveis por esses empreendimentos, preocupados com a manutenção de sua força de trabalho. Segundo Kowarick (2000, p. 26):

Até os anos 1930, quando começa a se ampliar a base produtiva ainda apoiada nos setores fabris tradicionais, principalmente a indústria têxtil e de alimentação, a acumulação industrial se concentrava em poucas 
empresas situadas em alguns pontos da Cidade. Nesse período, a expansão industrial processou-se de maneira bastante adensada, confundindo-se a vida nas fábricas e nos bairros operários.

Na cidade do Rio Grande, principalmente nas áreas portuárias e industriais, a produção de moradias populares estava diretamente relacionada a essas atividades.

Caracterizamos as ações voltadas ao planejamento e gestão das cidades, criadas a partir do século XXI, como um período marcado por uma nova política urbana, diferenciando-se do período anterior.

Em relação à criação do BNH, visto como uma iniciativa dos gestores públicos em pensar uma nova política habitacional, poderíamos afirmar que esse assumiu estratégias políticas e econômicas com intenções de atender uma demanda do setor urbano, através das empresas da construção civil, as quais movimentam um mercado importante, e também um caráter ideológico para restabelecimento da ordem social através da aquisição da casa própria, que daria ao indivíduo a condição de cidadão.

Esse sistema de financiamento da casa própria não consegue se manter em meio à crise econômica que vivencia o Brasil ao longo dos anos 1980, e sua extinção ocorre em meio a um aumento dos preços das construções, de aparecimento do ágio no preço dos materiais, da complexidade e do dinamismo da economia brasileira. Não tendo estrutura para solucionar as crises que foram surgindo na economia e política configurada, sua parte operacional passa a ser gerida pela Caixa Econômica Federal, ficando a parte normativa a cargo do Banco Central.

É importante constatar que os interesses dessas instituições financeiras não são compatíveis com os interesses sociais e com a problemática urbana,definida, entre outros fatores, pela falta de moradia e qualidade dos imóveis nas cidades. Desta forma a habitação popular não se torna um bom negócio, levando à extinção da própria instituição.

Na verdade, o problema da falta de moradia no Brasil segue sem solução, uma vez que ela é vistacomo qualquer outra mercadoria, principalmente num período em que o Brasil tem como objetivo estabelecer o desenvolvimento econômico capitalista.

0 fato é que as cidades brasileiras seguem crescendo com vários problemas urbanos, como moradias precárias, loteamentos irregulares e falta de infraestrutura, comprometendo a qualidade de vida das pessoas. Essa realidade é consequência da falta de políticas de planejamento e gestão urbanas, e de interesses no âmbito social, frente ao mercado que prevalece.

Da extinção do BNH até o início do século XXI, poucas ações e programas foram desenvolvidos no sentido de pensar uma política urbana, principalmente para as camadas da população de menor renda, a qual sempre teve difícil acesso à cidade na sua condição plena.
O que aqui denominamos como atual política urbana tem raízes, na verdade, no processo de redemocratização da sociedade brasileira que faz ressurgir os movimentos sociais urbanos, os quais começam a se articular em uma escala nacional. As causas defendidas como gênero, etnia, regularização de loteamentos e a situação de precariedade de vidas nas cidades já eram discutidas nas periferias, porém eram ações isoladas.

Consideramos um marco para a política urbana a proposta de Emenda Popular Urbana, apresentada na Assembléia Nacional Constituinte. A partir desse momento, tem início à possibilidade de se desenvolver um modelo de política e da cidade de forma mais democrática, voltada aos direitos sociais urbanos e à redistribuição do ônus que é produzido nesses espaços. A Constituição de 1988 traz modificações institucionais importantes para diversas instâncias, entre elas a organização das cidades e seu marco jurídico regulatório.

A Constituição de 1988, através da função social da propriedade tem por objetivo a promoção do interesse comum sobre o direito individual de propriedade, o uso socialmente justo e ambientalmente equilibrado do espaço urbano. Desta forma, busca a redistribuição indireta da renda e a orientação e o disciplinamento da expansão urbana, além do incentivo a determinadas atividades.

Neste contexto, o Estado assume uma importante função no sentido de implantação destas ações, pois é este, na instância municipal, que deverá identificar a função social da propriedade e da cidade, buscando minimizar os conflitos entre os interesses públicos e privados no território urbano.

Consideramos o compromisso dos municípios de fundamental importância para a efetividade de uma política urbana que vem sendo construída em escala nacional, uma vez que a não colaboração das esferas municipais e estaduais colocam em risco a possibilidade de reais mudanças no espaço da cidade. A cidade deve ser interpretada como um local de acesso a maior parte das camadas da população e não como um espaço cada vez mais privatizado, tanto pelas empresas como pelas próprias instituições públicas, uma vez que não promovem ações no sentido de democratizar o uso do espaço urbano.

A cidade é um espaço coletivo, desta forma deve ser pensada, não somente como um espaço de reprodução das relações capitalistas, mas como o estabelecimento de relações sociais, de convívio entre os diferentes e também de acesso à vida urbana. Assim, moldar sua gestão e planejamento a empresas e a iniciativa privada, muitas vezes, mediadas pela presença do Estado como agente regulatório, viola o seu verdadeiro conteúdo social. É com essas premissas que deve ser pensado o processo de uso do solo urbano, onde a participação social se torna uma condição para a garantia dos seus interesses.

Consideramos o Estatuto da Cidade, implementado em 2001, um instrumento da política urbana que 
traz importantes mudanças, uma vez que estabelece normas de ordem pública e de interesse social as quais regulam o uso da propriedade urbana a favor do uso coletivo, da segurança e do bem estar dos cidadãos, assim como do equilíbrio ambiental, buscando o pleno desenvolvimento das funções sociais da cidade e da propriedade urbana. Esse instrumento institui a política urbana nacional com o objetivo de ordenar o pleno desenvolvimento das funções sociais da cidade e da propriedade urbana, orientada pelas seguintes diretrizes:

I - garantia do direito a cidades sustentáveis, entendido como o direito à terra urbana, à moradia, ao saneamento ambiental, à infraestrutura urbana, ao transporte e aos serviços públicos, ao trabalho e ao lazer, para as presentes e futuras gerações;

II - gestão democrática por meio da participação da população e de associações representativas dos vários segmentos da comunidade na formulação, execução e acompanhamento de planos, programas e projetos de desenvolvimento urbano; [...]

IV - planejamento do desenvolvimento das cidades, da distribuição espacial da população e das atividades econômicas do município e do território sob sua área de influência, de modo a evitar e corrigir as distorções do crescimento urbano e seus efeitos negativos sobre o meio ambiente (BRASIL, 2001, Art. $2^{\circ}$, Incisos I, II e IV).

A criação desse arcabouço legal é resultado da luta dos movimentos sociais urbanos, os quais surgem devido ao rápido processo de urbanização no Brasil, atrelado aos problemas de segregação, falta de moradia e baixa qualidade de vida nas cidades, as quais têm a ocupação de seus espaços calcada na lógica capitalista, da terra como uma mercadoria.

Em 2003, a criação do Ministério das Cidades foi considerada um avanço na política urbana do país, produto da luta de lideranças sociais, profissionais e parcelas da sociedade preocupadas com a questão urbana, gerando uma expectativa nova para as cidades brasileiras, já que era fruto do processo de construção sustentado através de um amplo debate, como afirma Maricato (2011a, pp. 24-5):

Mas com o caminho que levou à criação do Ministério das Cidades teve uma pavimentação consolidada por muitos e sucessivos passos dados por um número cada vez maior de lideranças sociais, profissionais e técnicas de diversas origens. Um significativo número de documentos, projetos de lei, plataformas, programas foi desenvolvido pelo Fórum Nacional de Reforma Urbana, por cada uma das entidades que dele fizeram parte, pelos partidos políticos progressistas, pelas instâncias legislativas, pelas entidades sindicais, profissionais ou acadêmicas, e apresentados em fóruns internacionais (com destaque para a Conferência Internacional Habitat II, em 1996), nacionais e locais. 0 Ministério das Cidades foi fruto de um amplo movimento social progressista e sua criação parecia confirmar, com os avanços, os novos tempos para as cidades no Brasil. [...] Não se esperava nenhum grande e muito menos uma rápida mudança, já que havia algum conhecimento e experiência com gestão urbana municipal e metropolitana. Para os que tinham formação teórica sobre a produção capitalista do espaço urbano isso era ainda mais evidente. Mas era esperada, sim, a abertura de um canal para o qual convergisse a articulação de todos os que lidavam com os dramáticos $\mathrm{e}$ crescentes problemas urbanos, permitindo dessa forma ampliar e fortalecer o debate sobre como encaminhá-los e influir na correlação de forças de modo a encaminhar novas soluções. Parecia claro que esse encaminhamento levaria a construção social, e não apenas governamental, da Política Nacional de Desenvolvimento Urbano.

No ano de 2003 foi dado primeiro passo rumo à construção de uma Política Nacional de Desenvolvimento Urbano, na $1^{\text {a }}$ Conferência Nacional das Cidades, com o estabelecimento dos princípios e diretrizes da política urbana brasileira, através da participação de representantes de diferentes entidades de todo o território brasileiro.

A necessidade de estruturação de uma política urbana nacional vem no sentido de assegurar a qualidade de vida para os cidadãos e sustentabilidade para o crescimento futuro com bem estar nas cidades brasileiras. De acordo com a política urbana que vem sendo desenvolvida no Brasil, a reversão desse quadro exige a coordenação das ações governamentais de forma a assumir a política urbana como estratégica para o país, a universalização do acesso às políticas urbanas e a superação da cultura de uma gestão fragmentada, que separa a política de habitação das demais, como o saneamento ambiental e a mobilidade, gerando desperdício de recursos, ineficiência e reprodução das desigualdades socioespaciais.

Desta forma, a criação de um Sistema Nacional de Desenvolvimento Urbano (SNDU) vem da necessidade de coordenar as ações governamentais relacionadas às políticas urbanas de forma a universalizar o direito à moradia, em especial, o acesso à moradia digna, aos serviços de saneamento ambiental e à mobilidade urbana.

Os principais objetivos da política urbana brasileira são: a redução do déficit habitacional, o acesso universal ao saneamento ambiental, a mobilidade urbana com segurança, a democratização do acesso àinforma- 
ção, a diversificação de agentes promotores e financeiros, o planejamento e a gestão territorial, a qualidade ambiental urbana, a regulamentação e a aplicação do Estatuto da Cidade.

No ano de 2005, a Lei 11.124/2005 instituiu o Sistema Nacional de Habitação de Interesse Social (SNHIS), com o objetivo de implementar políticas e programas que promovam o acesso à moradia digna para a população de baixa renda. Essa Lei também instituiu o Fundo Nacional de Habitação de Interesses Social (FNHIS) que é composto por recursos do Orçamento Geral da União e do Fundo de Apoio ao Desenvolvimento Social (FAS), entre outros. Esses recursos são administrados por um conselho composto por representações de diversos segmentos da sociedade.

O SNHIS é um sistema nacional, descentralizado e democrático que unifica as políticas de habitação social e fomenta a produção de habitação de qualidade para a população de baixa renda, através da ação conjunta dos seus diversos agentes promotores. Ele pressupõe a existência de um conselho que garanta o direito à gestão democrática e atenda aos requisitos da Lei Federal № 11.124/2005, um fundo com dotação orçamentária específica e um Plano Municipal de Habitação de Interesse Social que identifique a demanda e as metas para minimizar o déficit habitacional do município. Essa política deve estar em consonância com a política de desenvolvimento urbano estabelecida no Estatuto da Cidade para dar cumprimento à função social da cidade e da propriedade através dos Planos Diretores Municipais, ou leis equivalentes.

Em 2009 foi editada a Lei $\mathrm{N}^{\circ} 11.977 / 2009$, com o objetivo de viabilizar o processo de regularização fundiária mais célere e eficaz com as diretrizes do Programa Minha Casa Minha Vida, representando avanços importantes para os processos de regularização fundiária, como, por exemplo, o Auto de Demarcação urbanística e a Legitimação da Posse. Em 2008, a Lei № 11.888 assegurou para as famílias de baixa renda o direito à assistência técnica para realização de projetos de habitação de interesse social.

O Programa Minha Casa Minha Vida (PMCMV), conforme o Art.1 ${ }^{\circ}$, da Lei que estabelece suas diretrizes, tem por finalidade criar mecanismos de incentivo à produção e aquisição de novas unidades habitacionais ou requalificação de imóveis urbanos e produção ou reforma de habitações rurais para famílias de baixa renda.

Na cidade do Rio Grande, o Programa Minha Casa Minha Vida vem atuando desde o ano de 2009, tanto com financiamento da Caixa Econômica Federal como de outros agentes financeiros. 0 quadro 1 indica o número de unidades habitacionais construídas na cidade até o determinado momento:

Quadro 1 - Número de unidades habitacionais, faixa de renda, valor do investimento, unidades habitacionais construídas e entregues em Rio Grande, do ano de 2009 a 2014

\begin{tabular}{|c|c|c|c|c|c|}
\hline $\begin{array}{c}\text { Agente } \\
\text { financiador }\end{array}$ & $\begin{array}{c}\text { Faixa de } \\
\text { renda }\end{array}$ & $\begin{array}{c}\text { Total de } \\
\text { unidades } \\
\text { habitacionais } \\
\text { (UH) }\end{array}$ & $\begin{array}{c}\text { Valor total do } \\
\text { investimento } \\
\text { (R\$) }\end{array}$ & $\begin{array}{c}\text { Unidades } \\
\text { habitacionais } \\
\text { concluídas }\end{array}$ & $\begin{array}{c}\text { Unidades } \\
\text { habitacionais } \\
\text { entregues }\end{array}$ \\
\hline \multirow{2}{*}{$\begin{array}{c}\text { Caixa } \\
\text { Econômica } \\
\text { Federal }\end{array}$} & Faixa 1 & $1.781 \mathrm{UH}$ & 23.218 .633 & $420 \mathrm{UH}$ & $418 \mathrm{UH}$ \\
\cline { 2 - 6 } & Faixa 2 & $1.178 \mathrm{UH}$ & 73.088 .164 & $1.178 \mathrm{UH}$ & $1.018 \mathrm{UH}$ \\
\hline \multirow{2}{*}{$\begin{array}{c}\text { Todos os } \\
\text { agentes }\end{array}$} & Faixa 3 & $301 \mathrm{UH}$ & 16.677 .083 & $301 \mathrm{UH}$ & $248 \mathrm{UH}$ \\
\cline { 2 - 6 } & Faixa 1 & $1.781 \mathrm{UH}$ & 23.218 .633 & $420 \mathrm{UH}$ & $418 \mathrm{UH}$ \\
\cline { 2 - 6 } & Faixa 2 & $1.382 \mathrm{UH}$ & 85.720 .568 & $1.182 \mathrm{UH}$ & $1.018 \mathrm{UH}$ \\
\hline
\end{tabular}

Fonte: Caixa Econômica Federal.

De acordo com o que pudemos observar, a CEF é o principal agente financiador do Programa, com um total de unidades habitacionais nas três faixas de renda de 3.269 e um valor total de investimentos de $\mathrm{R} \$$ 112.983.880. Somente a CEF obteve um número de 1.899 unidades habitacionais construídas e 1.684 entregues. Todos os agentes juntos somam 3.465 unidades habitacionais, um total de investimento de $\mathrm{R} \$$ 125.716.655, onde 1.904 foram construídas e 1.684 entregues.

Em relação às unidades habitacionais já entregues pelo PMCMV podemos destacar a construção de dois condomínios habitacionais destinados à população considerada de faixa 1 (um), ou seja, que possuem renda entre zero e três salários mínimos. 0 primeiro deles o Residencial Marcelino Champagnat, com 240 unidades habitacionais, e o segundo foi o Residencial São João, com 180. Os dois caracterizam-se por serem condomínios fechados, sendo o primeiro horizontal e o segundo vertical.

No processo de produção dos condomínios houve a participação dos seguintes agentes produtores do espaço urbano, o Estado, representado mediante a CEF, responsável pela a administração do Fundo de Arrendamento Residencial (FAR) e a Secretaria Municipal de Habitação e Desenvolvimento Urbano (SMHADU), através da doação do terreno e na seleção das famílias residentes no Residencial Marcelino Champagnat. No caso do Residencial São João, a seleção foi feita através do Movimento Nacional de Luta pela Moradia (MNLM) com posterior aprovação da CEF. Esses empreendimentos caracterizam-se por serem as primeiras políti- 
cas habitacionais voltadas à população de baixa renda, através de subsídios da CEF.

O Residencial Marcelino Champagnat está localizado no bairro Carreiros, em uma área composta por bairros e vilas populares, formadas em diferentes contextos históricos e processos socioespaciais diferenciados. Localiza-se a $12 \mathrm{~km}$ do centro da cidade, dispondo de uma infraestrutura urbana básica, carecendo ainda de melhores condições de mobilidade urbana, postos de saúde e escolas que atendam a demanda dessa área, bem como melhores condições de saneamento básico e segurança pública.

A distância em relação a uma infraestrutura adequada revela o processo de segregação espacial presente na produção do espaço urbano da maioria das cidades brasileiras, não sendo diferente no caso do Rio Grande. Essa área, localizada na zona oeste da cidade, pode ser considerada de uso residencial, utilizada principalmente pelas camadas mais populares da cidade.

Embora a criação do Residencial tenha sido uma ação do Estado, através do Programa Minha Casa Minha Vida, essas políticas ainda carecem de atenção, pois a produção de moradias não se trata somente da casa em si, e sim de uma série de infraestruturas que devem ser planejadas para a área a partir do momento em que se projeta um conjunto habitacional. Pôde-se perceber que no período de criação do Residencial, houve falta de vagas para as crianças nas escolas localizadas na área, de atendimento médico e uma intensa precariedade em relação ao transporte público, revelando que as áreas mais distantes e segregadas continuam sendo uma alternativa para localização das camadas mais populares, por parte do próprio Estado.

As cláusulas contratuais impedem a venda da casa adquirida pelo financiamento do PMCMV em um prazo de dez anos. Todavia, os moradores do residencial são proprietários desde o momento que assinaram os contratos com a CEF.

O Residencial São João, também distante do centro da cidade, e com carência de infraestrutura, foi construído no bairro São João. Assim como a área do Residencial Marcelino Champagnat, caracteriza-se por ser também de uso residencial popular, em que a principal característica foi a autoconstrução. 0 bairro destaca-se por ter sido um dos locais para onde foram realocadas as famílias do bairro Getúlio Vargas na década de 1960, sob a justificativa de expansão das atividades portuárias. A realocação das famílias para essa área demonstra uma característica bastante comum no processo de produção do espaço das cidades, a de distanciamento cada vez maior entre as camadas menos privilegiadas da população e a infraestrutura central, pois o bairro Getúlio Vargas está localizado em área central e próximo ao Porto do Rio Grande, onde muitos trabalhadores exercem suas atividades de trabalho.

Podemos perceber que a produção desses loteamentos acabam por resultar na valorização da terra urbana, pois ao chegar ao bairro a população não conta com uma infraestrutura necessária. Com o passar do tempo, vão conseguindo, através de intensas reivindicações, conquistar uma certa infraestrutura urbana de uso coletivo, tais como posto de saúde, escolas e pavimentação, além da consequente criação de estabelecimentos comerciais, que embora de pequeno porte, acabam cumprindo uma função no cotidiano dessas pessoas. Tal dinâmica acaba por gerar a valorização dessas áreas e uma possível nova expulsão das camadas mais pobres para áreas mais distantes.

No sentido de fazer com que as pessoas residentes do PMCMV não deixem os locais, vendendo suas casas e se deslocando para outras áreas ainda mais distantes, os subsídios para a compra do imóvel exige que este seja usado para fins de moradia, ficando proibida sua venda. Porém, a fiscalização e eliminação dessa prática é difícil de ser controlada.

No caso do Residencial Marcelino Champagnat, como já foi dito, o terreno pertencia a Prefeitura, no caso do São João, a terra era de propriedade da União, ou seja, ao Instituto Nacional de Seguridade Social (INSS). Essa foi convertida para o Fundo do Regime Geral da Previdência Social (FRGPS) e a União repassou alguns terrenos do FRGPS para o FAR, com o objetivo de construir habitação de interesse social dentro do PMCMV.

No ano de 2010, a CEF recebeu o pedido para dar início aos trâmites do processo de licitação para contratação da empresa que iria construir o Residencial São João. Esse empreendimento caracteriza-se por uma peculiaridade, neste caso, foi realizado a modalidade do PMCMV, na qual a seleção das famílias é realizada por uma entidade, que neste caso foi o MNLM. Esse é o segundo empreendimento no Brasil realizado com famílias selecionadas por entidades sem fins lucrativos.

A atuação de movimentos sociais urbanos no processo de seleção abre a possibilidade de se implantar uma nova lógica no que se refere à forma de pensar o espaço da cidade, pois esses segmentos da sociedade pensem o espaço urbano dentro de uma lógica diferente, em alguns aspectos, da lógica capitalista. Os movimentos urbanos interpretam a habitação como um local de uso residencial e para fins de moradia, e não como uma mercadoria qualquer que pode ser comprada e vendida com o intuito de especulação imobiliária.

Desta forma, a seleção das famílias que iriam residir nesse empreendimento não se definiria somente pela questão da renda, embora tenha sido um critério importante, uma vez que o empreendimento caracterizou-se por ser de interesse social, ou seja, destinado à população de zero a três salários mínimos, dependendo de fiscalização e aprovação da CEF.

\section{Considerações a modo de conclusão}

Percebemos através dos estudos desenvolvidos, que a cidade é o espaço materializado mediante as atividades produtivas, porém reflete também os mecanis- 
mos encontrados pela população para que esta tenha acesso à moradia, bem necessário para sua sobrevivência. No decorrer do processo de produção da cidade, as políticas públicas desenvolvidas não foram suficientes para suprir uma demanda habitacional crescente, frente ao excludente processo de ocupação do solo urbano. Os diferentes períodos de desenvolvimento econômico pelos quais a cidade do Rio Grande vivenciou, produziu muito mais uma demanda de trabalhadores sem acesso aos bens que a cidade deveria oferecer, do que a infraestrutura necessária para uma qualidade de vida adequada.

No decorrer do desenvolvimento desta sociedade industrial, a vida nas cidades e as novas relações de trabalho possibilitaram a luta política por melhores condições de vida. Chegamos ao século XXI, com um novo arcabouço legal que legitima a luta pela cidade, mas isso não é suficiente. Torna-se cada vez mais necessário, por parte da população, a apropriação da sua condição de cidadão, caso contrário, as cidades continuarão a se reproduzir segundo a lógica das atividades econômicas que as caracterizam.

Na verdade, a produção do espaço da cidade continua revelando estratégias de reprodução das relações capitalistas, que agora abrangem uma escala mundial cada vez mais excludente em relação às possibilidades de inserção nesse modelo de sociedade, e vai criando também suas contradições.

Os grandes projetos voltados para o crescimento econômico acelerado, como o processo de expansão portuária em Rio Grande, que faz parte de um programa nacional de governo, não vêm acompanhados de políticas públicas voltadas à melhoria da qualidade de vida das pessoas na cidade, muito menos apresenta propostas para os problemas estruturais que foram se agravando ao longo do tempo.

0 processo de produção da cidade é excludente, uma vez que é dado sob a hegemonia das relações capitalistas e continua a atingir as camadas mais vulneráveis da população. Embora o poder público venha lentamente buscando desenvolver políticas públicas que visem a uma maior igualdade social no uso do solo urbano, essas não atingem diretamente a raiz do problema, ou seja, a concentração da renda e a desigualdade socioespacial.

\section{Referências}

ALAMI, Sophie; DESJEUX, Dominique; GARABUAU-MOUSSAOUI, Isabelle. Os Métodos Qualitativos. Petrópolis: Vozes, 2010.

ARENDT, Hannah. O que é Política. Rio de Janeiro: Bertrand Brasil, 2013.

. A condição humana. Rio de Janeiro: Forense Universitária, 1999.

CARLOS, Ana Fani Alessandri. A reprodução do espaço urbano como momento da acumulação capitalista. In:
(Org.). Crise Urbana. São Paulo: Contexto, 2015.

. Da "organização" à "produção" do espaço no movimento do pensamento geográfico. In: CARLOS, Ana Fani Alessandri; SOUZA, Marcelo Lopes de; SPOSITO, Maria Encarnação Beltrão (Orgs.) A Produção do Espaço Urbano. Agentes e processos, escalas e desafios. São Paulo: Contexto, 2011a.

CASTRO, Iná Elisas de. Geografia e Política. Território, escalas de ação e instituições. Rio de Janeiro: Bertrand Brasil, 2009.

O espaço político local como condição de construção (mas também de negação) da democracia.In: BORZACCHIELLO, José; LIMA, Luiz Cruz; ELIAS, Denise (Orgs.). Panorama da Geografia Brasileira. Volume. 1. São Paulo: ANPEGE / Annablume, 2006.

CORRÊA, Roberto Lobato. 0 Espaço Urbano. São Paulo: Ática, 2002.

GANDRA, Edgar Avila. O bairro Getúlio Vargas sob o prisma das imagens. Revista do Instituto de Ciências Humanas e da Informação. Volume 12, 2000.

GOMES, Paulo César da Costa. A Condição Urbana. Ensaios de geopolítica da cidade. 2 ed. Rio de Janeiro: Bertrand, 2006.

HAESBAERT, Rogério. 0 Mito da Desterritorialização: do fim dos territórios à multiterritorialidade. Rio de Janeiro: Bertrand Brasil, 2004.

KOWARICK, Lúcio. Viver em risco. Sobre a vulnerabilidade socioeconômica e civil. São Paulo: Editora 34, 2009.

Escritos Urbanos. São Paulo: Editora 34, 2000.

LEFEBVRE, Henri. Espaço e política. Belo Horizonte: UFMG, 2008. 2002.

A Revolução Urbana. Belo Horizonte: UFMG,

0 Direito à Cidade. São Paulo: Moraes, 1991.

MARICATO, Ermínia. 0 impasse da política urbana no Brasil. Petrópolis: Vozes, 2011a.

MARTINS, Solismar Fraga; PIMENTA, Margareth Afeche. A constituição espacial de uma cidade portuária através dos ciclos produtivos industriais (1874-1970). Revista Brasileira de Estudos Urbanos e Regionais. Volume 6, Número 1, maio 2004.

MONBEIG, Pierre. O Estudo Geográfico das Cidades. Revista Cidades. Volume 1, número 2, 2004.

NASCIMENTO, Jonas Pereira do. Vantagens e limitações decorrentes da implantação da lei de modernização dos Portos. Dissertação (Mestrado em Engenharia de Transportes). Programa de Pós-Graduação em Engenharia - Universidade Federal do Rio de Janeiro, Rio de Janeiro, 2005. 
RIO GRANDE. Lei no. 6.585, de 20 de agosto de 2008: Dispõe sobre o plano diretor participativo do município do Rio Grande e estabelece as diretrizes e proposições de desenvolvimento urbano municipal. Prefeitura Municipal do Rio Grande. Estado do Rio Grande do Sul. Rio Grande, 2008a.

Lei no. 6.588, de 20 de agosto de 2008: estabelece o regime urbanístico do município do Rio Grande, normatizando o zoneamento de uso e ocupação do solo, os dispositivos de controle das edificações, equipamentos urbanos e procedimentos administrativos. Prefeitura Municipal do Rio Grande. Estado do Rio Grande do Sul. Rio Grande, 2008b.

ROLNIK, Raquel. 0 que é cidade. São Paulo: Brasiliense, 1995.

SANTOS, Milton. 0 Espaço do Cidadão. São Paulo: Edusp,
2007.

A Natureza do Espaço Técnica e Tempo Razão e Emoção. São Paulo: Hucitec, 1997.

SOARES, Paulo Roberto Rodrigues; AMARAL, Stella Maris Ricardo do. Reestruturação do Espaço Urbano: A produção capitalista de moradias em Rio Grande/RS (os condomínios verticais). Boletim Gaúcho de Geografia. № 22, 1997.

SOUZA, Marcelo Lopes de. Os Conceitos Fundamentais da Pesquisa Sócio-espacial. Rio de Janeiro: Bertrand Brasil, 2013.

Mudar a Cidade: Uma introdução Crítica ao Planejamento e Gestão Urbanos. Rio de Janeiro: Bertrand Brasil, 2002. 